\title{
In vitro biomechanical comparison of headless compression versus cortex screws for fixation of simulated midbody proximal sesamoid bone fractures in horses
}

\author{
Marco F. Bryner' ${ }^{7}$ Sebastian Valet ${ }^{2}$, Bernhard Weisse ${ }^{2}$, Anton E. Fürst' ${ }^{7}$ and Jan M. Kümmerle \\ 'Equine Department, Vetsuisse Faculty, University of Zurich, Zurich, Switzerland \\ 2 EMPA, Swiss Federal Laboratories for Materials Science and Technology, Dübendorf, Switzerland
}

\begin{abstract}
Summary: A midbody fracture of a proximal sesamoid bone (PSB) is a severe injury, especially in racehorses. Screw fixation may be the only option for horses to return to athletic activity. In a cadaveric biomechanical study, fixation of simulated transverse midbody PSB fractures with a $4.5 \mathrm{~mm}$ headless compression screw (HCS) was compared to the fixation using a $4.5 \mathrm{~mm}$ cortex screw (CS) inserted in lag fashion. The front limbs of 8 horses were prepared with a standardized midbody transverse osteotomy in each medial PSB. The left or the right limb of each pair was randomly assigned to the CS or HCS group. Fracture reduction and fixation was controlled by radiography. Markers were fixed proximal and distal to the osteotomy to document gap opening by an image correlation measurement. Cyclic compressive loading was applied with a hydraulic cylinder in an axial manner leading to tensile cyclic loading in the PSBs. After mechanical testing all limbs were radiographed to document the mode of failure. The mean cycles to total failure were 27,803 for the HCS group and 36,624 for the CS group, respectively. A mean of 14,444 cycles (HCS group) versus 27,464 cycles (CS group) was recorded at a fracture gap opening of $10 \%$. The mean value of initial stiffness was $300 \mathrm{~N} / \mathrm{mm}$ (HCS group) versus $590 \mathrm{~N} / \mathrm{mm}$ (CS group). On post-testing radiographs, failure by screw breakage was detected in 3/8 limbs of the HCS group and in 2/8 limbs of the CS group. Screw pullout and bone failure was noted in 5 limbs in each group. In one limb of the CS group, the medial suspensory branch was disrupted and the fracture fixation was intact. None of the differences between HCS and CS constructs reached statistical significance. However, the lower absolute numbers of cycles sustained before failure, at $10 \%$ gap opening and lower initial stiffness of HCS constructs as well as limitations of the study warrant further investigation before clinical use of the HCS for this indication can be recommended.
\end{abstract}

Keywords: proximal sesamoid bone, fracture, headless compression screw, cycling loading, horses

Citation: Bryner M. F., Valet S., Weisse B., Fürst E., Kümmerle M. (2019) In vitro biomechanical comparison of headless compression versus cortex screws for fixation of simulated midbody proximal sesamoid bone fractures in horses. Pferdeheilkunde 35, 396-402; DOI 10.21836/ PEM20190501

Correspondence: Prof. Dr. Anton Fürst, Equine Department, Vetsuisse Faculty University of Zurich, Winterthurerstrasse 260, 8057 Zurich, Switzerland; afuerst@vetclinics.uzh.ch

Received: July 17, 2019 | Accepted: August 10, 2019

\section{Introduction}

Fractures of the proximal sesamoid bones (PSB) are relatively common injuries in athletic horses, especially racehorses (Nixon 2019). PSB fractures were the most frequent fatal bone injury in Thoroughbred horses while racing (50\%) or training (30\%) observed over a 2-year period in California (Johnson et al. 1994). In a recent overview of fractures in racing Thoroughbreds at the Hong Kong Jockey Club between 2004 and 2011 , fractures of the PSB represented $55 \%$ of all catastrophic fractures (Sun et al. 2019).

While arthroscopic fragment removal or conservative treatment is indicated for apical fractures involving up to one third of the proximodistal dimension of the PSB, abaxial and basilar fractures, internal fixation is required for midbody fractures (Wright 2018, Nixon 2019). Multifragment and biaxial fractures represent severe breakdown injuries because of disruption of the suspensory apparatus and usually require fetlock arthrodesis or euthanasia (Nixon 2019).
For internal fixation of uniaxial transverse midbody fractures of the PSB, circumferential cerclage wire or a lag screw is required to achieve adequate fracture union (Wright 2018). Busschers et al. (2008) suggested that screw fixation is the only option for racehorses to return to athletic activity. Interfragmentary screw fixation in lag fashion returns up to $60 \%$ of Thoroughbred horses to active racing (Henninger et al. 1991, Martin et al. 1991, Wheeler and McLoughlin 1998).

The headless compression screw (HCS) is a well-established implant in human medicine for fixation of intra-/extraarticular fractures, nonunions or arthrodeses of small bones. It is used for scaphoid and other carpal/tarsal bone fractures, fractures of the patella as well as for radial head and styloid fractures (DePuy Synthes 2017). The advantage of the HCS is that the screw head can be countersunk in the bone, thus avoiding impingement of the screw head into surrounding soft tissue or cartilaginous surfaces (Galuppo et al. 2006). Furthermore, this screw is cannulated, the head and the tip are tapered and it is inserted over a preplaced pin, which facilitates ac- 
curate screw placement in small bones. Successful clinical use of the HCS in equine surgery was reported for repair of nondisplaced lateral condylar fractures and for slab fractures of the third carpal bone (Galuppo et al. 2006, Hirsch et al. 2007).

Both the apical and the basilar aspects of the equine PSB are associated with essential soft tissues, i.e. the suspensory ligament and the distal sesamoidean ligaments, respectively. In such an environment, the features of the HCS could be beneficial in terms of avoiding damage to these structures resulting from interference with protruding screw heads.

The purpose of this biomechanical study was to compare the stability and fatigue strength of a simulated medial midbody PSB fracture after fixation with a $4.5 \mathrm{~mm}$ HCS versus a $4.5 \mathrm{~mm}$ cortex screw (CS) implanted in lag fashion. Our hypothesis was that fixation using a HCS would result in similar resistance to cyclic loading compared to a construct using a cortex screw.

\section{Material and methods}

The front limbs of 8 horses euthanized for reasons unrelated to this study and without any known pathology of the PSBs and the suspensory apparatus were prepared and stored as described by Eddy et al. 2004. In each limb a standardized midbody transverse osteotomy was created in the medial PSB using an oscillating saw. The osteotomy was created under fluoroscopic control in such a manner that the proximal fragment represented $40 \%$ and the distal fragment $60 \%$ of the proximodistal length of the PSB. The bone was cooled using a $\mathrm{NaCl} 0,9 \%$ rinse during sawing. The lateral PSB was left intact in all limbs. The left or the right limb of each pair was randomly assigned to the CS or HCS group.

The osteotomy was fixed with a reduction forceps applied to the basal and apical aspect of the medial PSB. The base of the medial PSB was approached by a longitudinal incision between the origins of the straight distal sesamoidean ligament and the oblique distal sesamoidean ligament. Screw insertion was guided by fluoroscopic control.

In the HCS group, a single $4.5 \mathrm{~mm}$ stainless steel HCS (DePuy Synthes, Synthes USA Products, Pennsylvania, USA) was implanted via this approach while a single stainless steel $4.5 \mathrm{~mm}$ cortex screw (DePuy Synthes, Synthes USA Products, Pennsylvania, USA) was inserted in lag fashion in the CS group.

The first step to place a HCS was insertion of a $1.6 \times 150 \mathrm{~mm}$ guide wire which was drilled through the drill guide into the bone until the threaded tip was anchored in the far cortex. The guide wire was placed in the middle of the base of the PSB and as perpendicular to the osteotomy as possible. Screw length was determined with the measuring device slid over the guide wire. A drill hole was created by sliding the drill guide with a $3.2 \mathrm{~mm}$ cannulated drill bit over the guide wire. To ensure that the guide wire stayed in place, the drill hole was stopped before the tip of the guide wire was reached. The threads were cut manually using a $4.5 \mathrm{~mm}$ cannulated tap and a $4.5 \mathrm{~mm}$ cannulated HCS was inserted over the guide wire. All screws were placed and tightened manually using the compression sleeve until the osteotomy was reduced and compressed. The HCS was countersunk using a cannulated screw driver with color markings to control the degree of countersinking. The hard and dense bone in this region required pre-drilling of the space accommodating the head of the HCS.

In the CS group, a $4.5 \mathrm{~mm}$ cortex screw was inserted in lag fashion. A $4.5 \mathrm{~mm}$ glide hole was drilled in the basilar PSB fragment to the level of the osteotomy. A $3.2 \mathrm{~mm}$ drill sleeve was inserted in the glide hole and a $3.2 \mathrm{~mm}$ thread hole was drilled through the apical part of the bone. A depression for the screw head was prepared with the countersink and the depth gauge used to determine screw length. The threads were cut into the thread hole using the tap and a $4.5 \mathrm{~mm}$ cortex screw was implanted in lag fashion.

The specimens were radiographed (lateromedial and dorsomedial-palmarolateral oblique views) to evaluate fracture fixation and screw position. The limbs were prepared with a polymethylmethacrylate (PMMA, Technovit 3040 from Kulzer GmbH, Wehrheim, Germany) imbedding at the level of the distal and proximal carpal bone rows for fixation in the mechanical testing machine at the proximal end $(20 \mathrm{kN}$ hydraulic cylinder with Instron IST control unit 8800, Norwood, Massachusetts, USA; $50 \mathrm{kN}$ load cell from GTM, Testing and Metrology, Bickenbach, Germany). Two markers were fixed at the PSB $5 \mathrm{~mm}$ proximal and distal to the osteotomy, respectively, using PMMA to document gap opening by an image correlation measurement (camera: ECO655 MVGE, Monochrome $2448 \times 2050$ Pixel, mounted with a $f=40 \mathrm{~mm}$ lens, SVS Vistek, Seefeld, Germany, analysis with MatroxTM Image Design Assistant, Quebec, Canada). The hoof was placed in a support designed to allow normal fetlock joint movement and immobilized with 2 screws on each side (Figure 1).

Cyclic compressive loading to the limb was performed with a hydraulic cylinder in an axial manner at $1 \mathrm{~Hz}$ with an initial upper load of 1000 Newton (N). The load was increased every 5,000 cycles by $400 \mathrm{~N}$.

The total number of load cycles before failure were recorded. The number of load cycles until the fracture gap reached an opening of $10 \%$ and until the stiffness reduction rose to $50 \%$, respectively, were documented. After mechanical testing all limbs were radiographed to document the mode of failure.

Test result groups of each test parameter used for statistical analysis were first checked for normal distribution using a Kolmogorov-Smirnov test (OriginLab Corporation, Northampton, United States). Tests groups were compared and checked for significant difference of mean values using a paired twotailed t-test with $\mathrm{p}$ set $<0.05$.

\section{Results}

Fracture fixation as evaluated by radiographs was adequate in 15/16 operated limbs. One specimen of the HCS group (Horse 5, Table 1) had mildly incomplete fracture reduction on pre-testing radiographs. The median screw length was $32 \mathrm{~mm}$ in the HCS group and $37 \mathrm{~mm}$ in the CS group. All result parameters were normally distributed. 

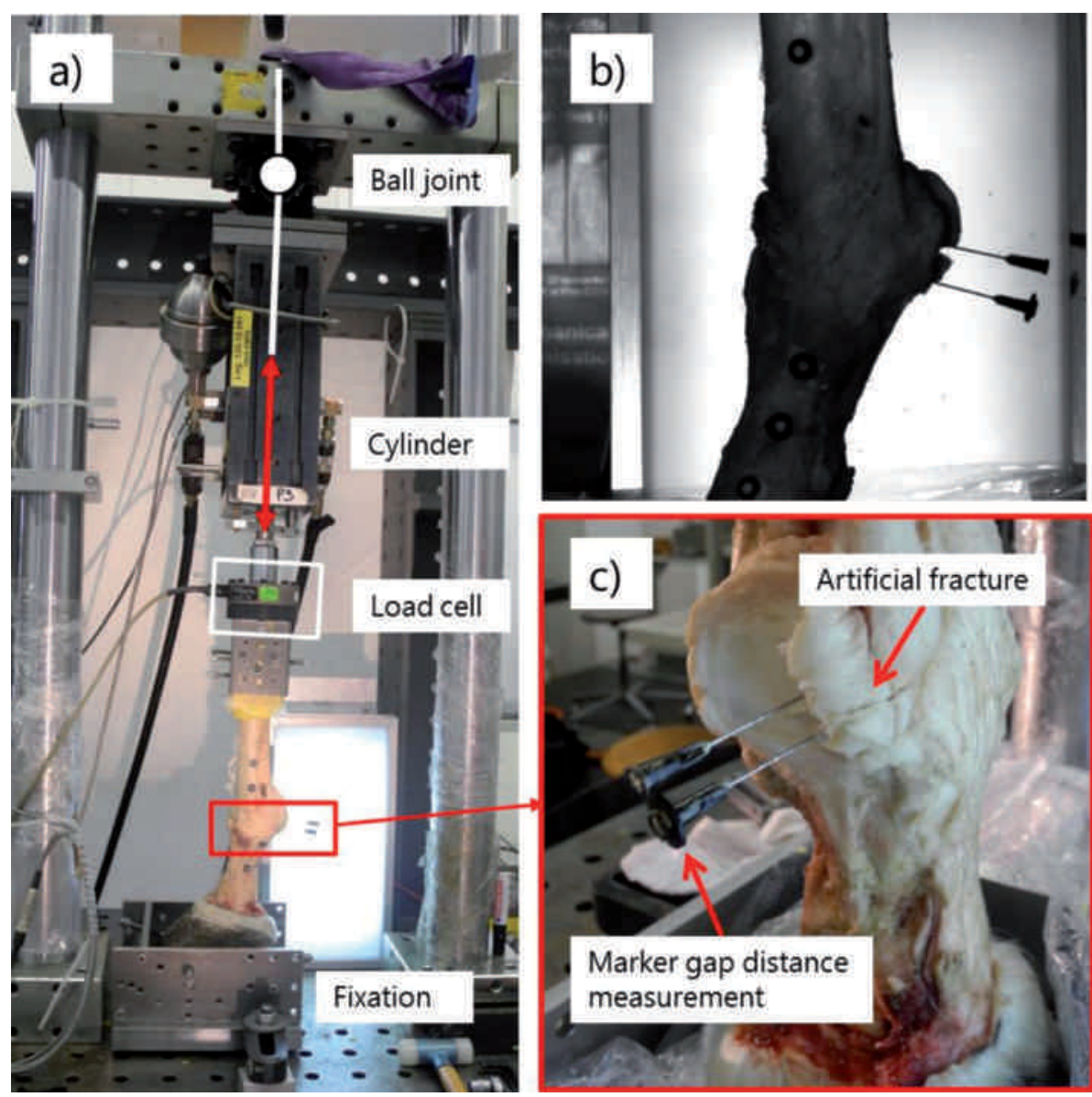

Fig. 1 Illustration of the test setup. a) Overview of the testing construct with the limb fixed in the testing machine for cycling compressive loading. $b \& c)$ Two markers were attached to the PSB, proximal and distal to the osteotomy, to document fracture gap opening by an image correlation measurement. Illustration des Testaufbaus. a) Übersicht des Prüfkonstrukts mit einer für die zyklische Belastung in der Testmaschine fixierten Gliedmaße. b\&c) Zwei Marker wurden proximal und distal der Osteotomie angebracht, um die Öffnung des Frakturspalts mit einer Bildkorrelationsmessung zu dokumentieren.

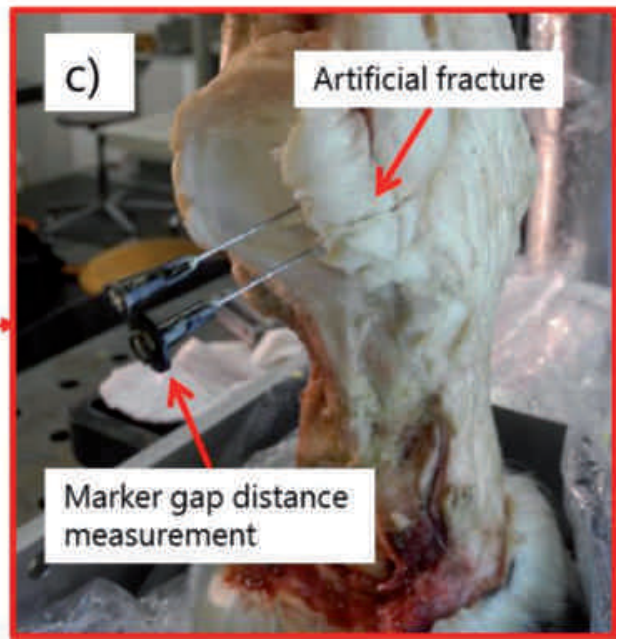

Table 1 Legs and types of screws, number of cycles and type of failure | Gliedmaßen und Schraubenart, Anzahl Belastungszyklen und Art des Versagens

\begin{tabular}{|c|c|c|c|c|c|c|}
\hline Horse & Leg & Screw type & Screw length (mm) & $\begin{array}{c}\text { Number of } \\
\text { cycles until fixation } \\
\text { failure }\end{array}$ & $\begin{array}{l}\text { Number of cycles } \\
\text { until the fracture } \\
\text { gap opens } 10 \%\end{array}$ & Type of failure \\
\hline 1 & right & CS & 38 & 32,859 & 32,126 & screw pull out \\
\hline 1 & left & $\mathrm{HCS}$ & 32 & 27,912 & 17,724 & screw break \\
\hline 2 & left & CS & 34 & 35,896 & 33,509 & screw pull out \\
\hline 2 & right & HCS & 32 & 30,742 & 25,599 & screw pull out \\
\hline 3 & right & CS & 34 & 34,800 & 12,190 & screw break \\
\hline 3 & left & $\mathrm{HCS}$ & 34 & 27,860 & 12,185 & screw break \\
\hline 4 & right & CS & 40 & 30,801 & 12,796 & screw pull out \\
\hline 4 & left & $\mathrm{HCS}$ & 36 & 21,205 & 6,103 & screw break \\
\hline 5 & left & CS & 40 & 81,623 & 75,483 & intact fixation/SL disruption \\
\hline 5 & right & $\mathrm{HCS}$ & 38 & 40,271 & 10,358 & screw pull out \\
\hline 6 & right & CS & 30 & 23,831 & 23,820 & screw break/SL disruption \\
\hline 6 & left & HCS & 24 & 36,889 & 36,881 & screw pull out \\
\hline 7 & left & CS & 38 & 33,001 & 13,131 & screw pull out \\
\hline 7 & right & $\mathrm{HCS}$ & 28 & 19,000 & 1,219 & screw pull out \\
\hline 8 & left & CS & 36 & 21,298 & 5,483 & screw pull out \\
\hline 8 & right & $\mathrm{HCS}$ & 26 & 18,915 & 15,851 & screw pull out \\
\hline
\end{tabular}

$\mathrm{CS}=$ cortex screw, Kortikalisschraube; HCS = headless compression screw, kopflose Kompressionsschraube; SL = suspensory ligament, Fesselträger 
The mean cycles to failure were 27,803 for the HCS group $(S D=7,472)$ and 36,624 for the CS group ( $S D=18,854)$. A mean of 14,444 cycles (HCS group, $S D=11,863$ ) versus 27,464 cycles (CS group, $S D=21,294$ ) was recorded at a

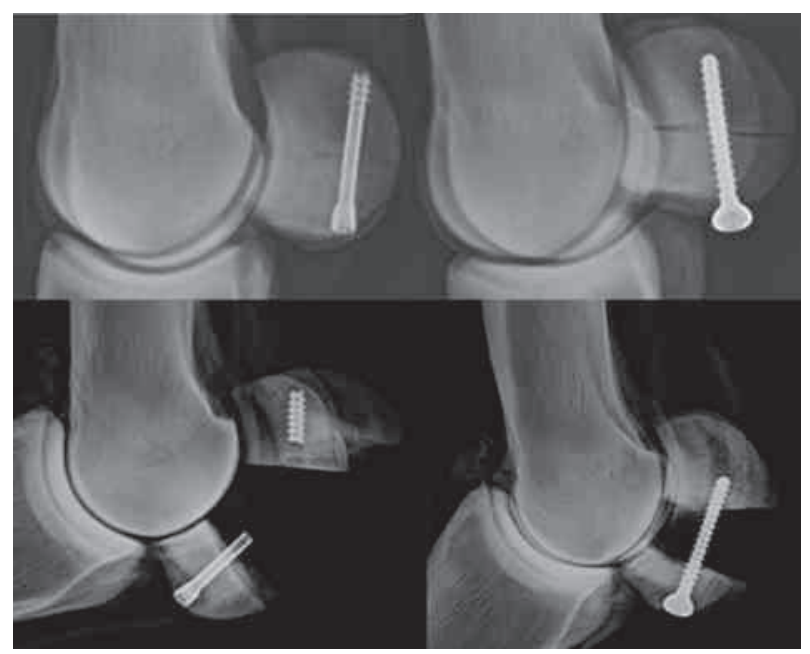

Fig. 2 Pre- (top row) and post- (bottom row) testing lateromedial fetlock radiographs from horse 4 . The headless compression screw (left) broke after 21,205 cycles and the cortex screw (right) was pulled out of the apical proximal sesamoid bone fragment after 30,801 cycles. | Lateromediale Fesselgelenk Röntgenbilder von Pferd 4 vor (obere Reihe) und nach (untere Reihe) der zyklischen Belastung. Die kopflose Kompressionsschraube (links) brach nach 21.205 Zyklen und die Kortikalisschraube (rechts) wurde nach 30.801 Zyklen aus dem apikalen Knochenfragment des Gleichbeins herausgerissen. fracture gap opening of $10 \%$ (Figure 3). The mean of the corresponding failure load values was 3,006 N (HCS group, $\mathrm{SD}=930 \mathrm{~N}$ ) versus $3,931 \mathrm{~N}(\mathrm{CS}$ group, $\mathrm{SD}=1,584 \mathrm{~N})$, respectively. The mean value of initial stiffness was $300 \mathrm{~N} / \mathrm{mm}$ (HCS group) versus $590 \mathrm{~N} / \mathrm{mm}$ (CS group), respectively.

None of these differences between the HCS and the CS group was statistically significant $(p<0.05)$.

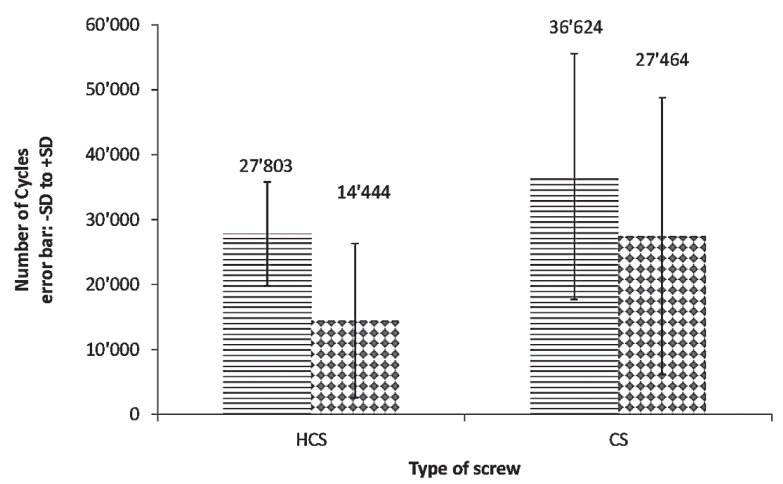

Fig. 3 Comparison of mean number of load cycles sustained before failure (left column for each group) and at $10 \%$ gap opening (right column for each group) between the HCS and the CS group. I Vergleich der durchschnittlichen Anzahl der Lastzyklen vor dem Versagen (linke Säule für jede Gruppe) und bei 10\% Frakturspaltöffnung (rechte Säule für jede Gruppe) zwischen der HCS- und der CS-Gruppe.

$=$ Cystes total $/$ Cycles estimate $10 \%$ opening (image-corr.)

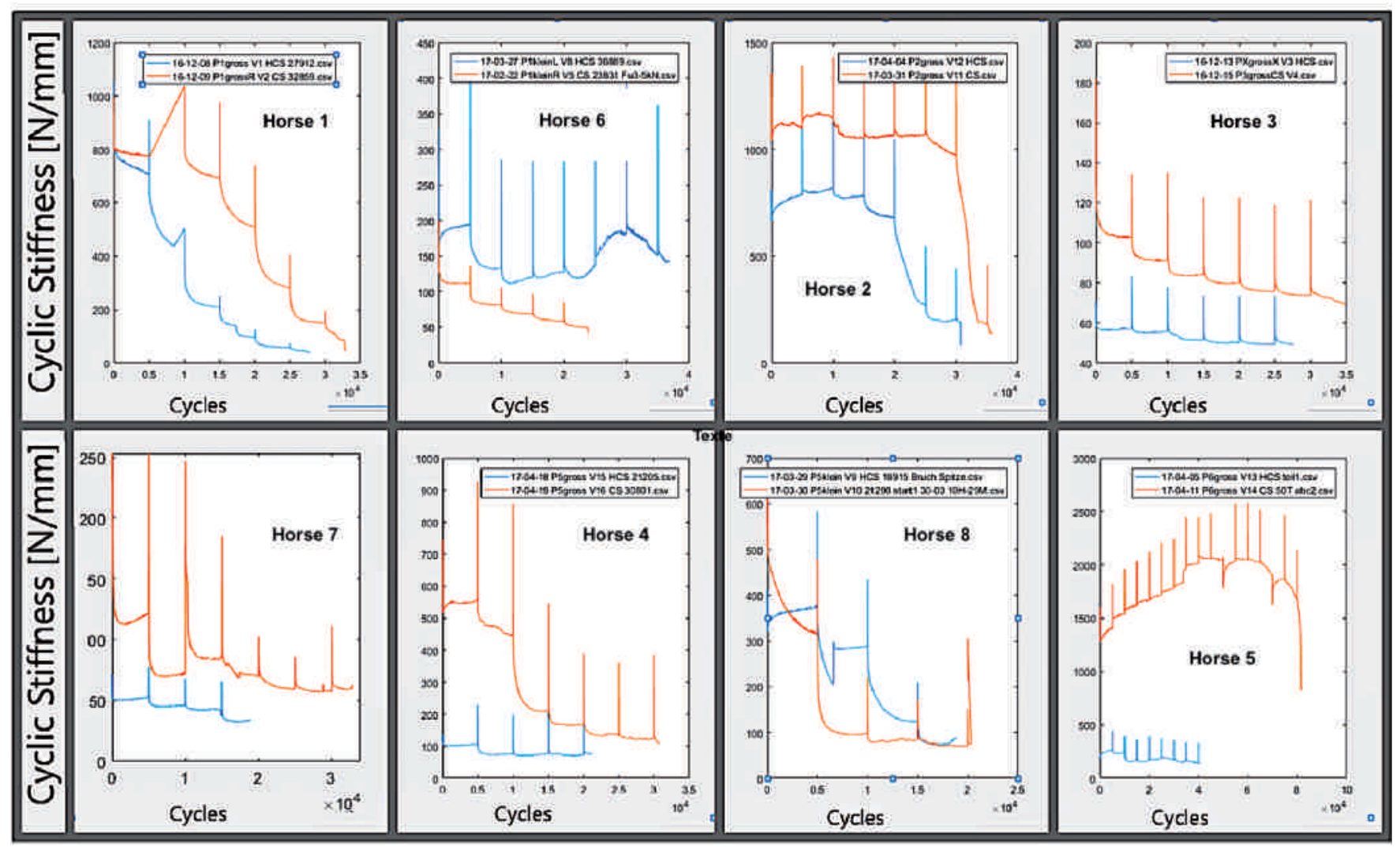

Fig. 4 Cyclic stiffness trend plots of all tested bone pairs. HCS = blue curves, $C S=$ red curves. Ratio values of various result parameters (calculated for each bone pair). The limbs fixed with a CS tend to have a higher stiffness than these fixed with HCS. | Trenddiagramme der zyklischen Steifigkeit aller getesteten Knochenpaare. HCS = blave Kurven, CS = rote Kurven. Verhältniswerte verschiedener Ergebnisparameter (berechnet für jedes Knochenpaar). Für Konstrukte mit einer CS gibt es einen Trend zu einer größeren Steifigkeit im Vergleich zur HCS Gruppe. 
On post-testing radiographs, failure by screw breakage was detected in 3/8 limbs of the HCS group and in 2/8 limbs of the CS group. In one specimen (Horse 6, Table 1) of these two cases in the CS group, the lateral branch of the suspensory ligament was ruptured in addition to screw breakage. Screw pullout and bone failure was noted in 5 limbs in each group (Figure 2). In one limb of the CS group (Horse 5, Table 1), the medial suspensory branch was disrupted and the fracture fixation was intact.

\section{Discussion}

This study did not find significant differences in resistance towards cyclic loading between simulated mid-body transverse fractures of the medial PSB stabilized with either a $4.5 \mathrm{~mm}$ cortex screw (CS) inserted in lag fashion or with a $4.5 \mathrm{~mm}$ cannulated headless compression screw (HCS). However, the fixation with a HCS showed a trend to be less stable and weaker compared to fixation using a CS. The means of initial stiffness, of the corresponding failure load values, of the number of cycles at total failure and of the number of cycles at 10\% fracture gap opening were smaller in the HCS group than in the CS group.

Studies comparing biomechanical properties of fixations using the HCS versus a CS under cyclic loading conditions are sparse. A human cadaveric study found no differences between stability of simulated radial head fractures repaired with either a $3.0 \mathrm{~mm}$ HCS or a $2.0 \mathrm{~mm}$ CS (Burkhart et al. 2010).

In equine orthopaedics, a different headless compression screw (Acutrak) which is tapered and has a variable pitch was suggested for third carpal bone fracture repair (Bueno et al. 2003), lateral third metacarpal condylar fractures (Galuppo et al. 2001, Galuppo et al. 2006), proximal interphalangeal joint arthrodesis (Wolker et al. 2009) and even for repair of midbody PSB fractures (Eddy et al. 2004) based on biomechanical studies that found similar stability compared to that achieved with use of a CS. However, these studies relied on single cycle to failure testing and cyclic loading was not performed. The screws used in these four studies are tapered over their whole length and have a variable pitch, which represents a significant difference to the design of the HCS screw from Synthes that has a non-tapered shaft. Furthermore, biomechanical testing performed in cyclic fashion as performed in our study is clinically more relevant as it more closely mimicks the clinical situation and results are hardly comparable to single cyclic testing.

Failure by screw breakage was more frequent in the HCS group. This might be attributed to differences in implant design: the HCS is cannulated which reduces the area moment of inertia and thus bending stiffness.

It is interesting to compare the biomechanical loads achieved at failure to the forces present in the in vivo situation. In vivo, the vertical ground reaction force in Warmblood horses has been documented as $7 \mathrm{~N} / \mathrm{kg}$ $(3.5 \mathrm{kN} / 500 \mathrm{~kg}$ ) at the walk for forelimbs (Merkens et al. 1988). This is in the range of mean failure loads $(3.0 \mathrm{kN}$ for the HCS constructs, $3.9 \mathrm{kN}$ for the CS constructs) achieved in our study. Concerning number of cycles to failure, it is known that healthy horses confined to a box in a new envi- ronment make a mean of 4,560 steps in 24 hours (McDuffee et al. 2000). This would mean that the mean number of cycles sustained before failure would be reached in 8 days for the CS constructs and 6 days for the HCS constructs, respectively. However, several characteristics of the ex vivo situation during biomechanical testing impair cyclic fatigue life, e.g. the lack of other supporting structures such as the flexor tendons, lack of muscular activity, lack of protection by a cast, and lack of the protective effect of pain.

Our study is not without limitations. Some limitations are associated with the cadaveric nature of the specimens, e.g. lack of muscular activity and changes in tissue properties during limb preparation and storage. Other limitations were introduced with preparation of the limbs to allow installation into the testing machine, e.g. removal of additional supporting structures such as the flexor tendons. Although a standardized technique was used for screw implantation, some degree of variability concerning screw position was present which could influence cyclic fatigue behavior and might explain the high standard deviation in our results. Furthermore, the threadless shaft of the HCS means that interfragmentary compression forces can vary based on fracture location (Patel et al. 2017). The suboptimal fracture fixation detected on pretesting radiographs in the right limb of horse 5 had no negative effect on the number of cycles until failure or until fracture gap opening of $10 \%$. Finally, the limited number of specimens combined with a high standard deviation could lead to a type II error, i.e. erroneous acceptance of the null hypothesis that there are no differences between HCS and CS constructs.

In conclusion, this study did not find significant differences in cyclic fatigue behaviour of simulated midbody transverse PSB fractures repaired with either a HCS or a CS applied in lag fashion. However, the lower absolute numbers of cycles sustained before failure, at 10\% gap opening and lower initial stiffness of HCS constructs as well as limitations of the study warrant further investigation before clinical use of the HCS for this indication can be recommended.

\section{Financial support}

No financial support was received for this study.

\section{Conflict of interest statement}

The authors declare no conflict of interest related to this study.

\section{References}

Bueno A. C., Galuppo L. D., Taylor K. T., Jensen D. G., Stover S. M., Mueller L. P. (2003) A biomechanical comparison of headless tapered variable pitch and $A O$ cortical bone screws for fixation of a simulated slab fracture in equine third carpal bones. Vet. Surg. 32 167-177; DOI 10.1053/jvet.2003.50019

Burkhart K. J., Novak T. E., Appelmann Ph., Sternstein W., Rommens P. M., Mueller L. P. (2010) Screw fixation of radial head fractures: Compression screw versus lag screw - A biomechanical comparison. Injury, Int. J. Care Injured 41, 1015-1019; DOI 10.1016/i. injury.2010.03.001 
Busschers E., Richardson D. W., Hogan P. M., Leitch M. (2008) Surgical repair of mid-body proximal sesamoid bone fractures in 25 horses. Vet. Surg. 37, 771-780; DOI 10.1111/j.1532950X.2008.00445.x

DePuy Synthes (2009-2017) $4.5 \mathrm{~mm}$ and $6.5 \mathrm{~mm}$ Headless Compression Screws Technique Guide, Product Brouchure, http://synthes.vo.llnwd.net

Eddy A. L., Galuppo L. D., Stover S. M., Taylor K. T., Jensen D. G. (2004) A biomechanical comparison of headless tapered variable pitch compression and $\mathrm{AO}$ cortical bone screws for fixation of a simulated midbody transverse fracture of the proximal sesamoid bone in horses. Vet. Surg. 33, 253-262; DOI 10.1111/j.1532950X.2004.04037.x

Galuppo L. D., Simpson E. L., Greenman S. L., Dowd J. P., Ferraro G. L., Meagher D. M. (2006) A clinical evaluation of a headless, titanium, variable-pitched, tapered, compression screw for repair of nondisplaced lateral condylar fractures in thoroughbred racehorses. Vet. Surg. 35, 423-430; DOI 10.1111/j.1532. 950X.2006.00170.x

Galuppo L. D., Stover S. M., Jensen D. G., Willits N. H. (2001) A biomechanical comparison of headless tapered variable pitch and $\mathrm{AO}$ cortical bone screws for fixation of a simulated lateral condylar fracture in equine third metacarpal bones. Vet. Surg. 30, 332-340

Henninger R. W., Bramlage L. R., Schneider R. K., Gabel A. A. (1991) Lag screw and cancellous bone graft fixation of transverse proximal sesamoid bone fractures in horses: 25 cases (1983-1989). J. Am. Vet. Med. Assoc. 199, 606-612

Hirsch J. E., Galuppo L. D., Graham L. E., Simpson E. L., Ferraro G. L. (2007) Clinical evaluation of a titanium, headless variable-pitched tapered cannulated compression screw for repair of frontal plane slab fractures of the third carpal bone in thoroughbred racehorses. Vet. Surg. 36, 178-184: DOI 10.1111/i.1532950X.2007.00251.x
Johnson B. J., Stover S. M., Daft B. M., Kinde H., Read D. H., Barr B. C., Anderson M., Moore J., Woods L., Stoltz J., Blanchard P. (1994) Causes of death in racehorses over a 2 -year period. Equine Vet. J. $26,327-330$

Martin B. B., Nunamaker D. M., Evans L. H., Orsini J. A., Palmer S. E. (1991) Circumferential wiring of mid-body and large basilar fractures of the proximal sesamoid bone in 15 horses. Vet Surg. 20, 9-14

McDuffee L. A., Strover S. M., Coleman K. (2000) Limb loading activity of adult horses confined to box stalls in an equine hospital barn. Am. J. Vet. Res. 61, 237-237

Merkens H. W., Schamhardt H. C., Hartman W., Kersjes A. W. (1988) The use of Horse (INDEX), a method of analyzing the ground reaction force patterns of lame and normal gaited horses at the walk. Equine Vet. J. 20, 29-36

Nixon A. J. (2019). Phalanges and the Metacarpophalangeal and Metatarsophalangeal Joints. In: Auer J. A., Stick J. A., Kümmerle J. M., Prange T. (eds) Equine Surgery. 5th ed., Elsevier Saunders, St. Louis, 1587-1618

Patel S., Tiedeken N., Qvick L., Debski R. E., Kaufmann R., Fowler J. R. (2017) Interfragmentary compression forces vary based on scaphoid bone screw type and fracture location. Hand 14, 371376; DOI 10.1177/1558944717745663

Sun T. C., Riggs C. M., Cogger N., Wright J., Al-Alawneh J. I. (2019) Noncatastrophic and catastrophic fractures in racing Thoroughbreds at the Hong Kong Jockey Club, Equine Vet. J. 51, 77-87; DOI 10.1111 evj.12953

Wheeler D. L., McLoughlin S. W. (1998) Biomechanical assessment of compression screws. Clin. Orthop. Relat. Res. 350, 237-45

Wolker R. R., Carmalt J. L., Wilson D. G. (2009) Arthrodesis of the equine proximal interphalangeal joint: a biomechanical comparison of two parallel headless, tapered, variable-pitched, titanium compression screws and two parallel $5.5 \mathrm{~mm}$ stainless-steel cortical screws. Vet. Surg. 38, 861-867 DOl 10.1111/j.1532-950X.2009.00574.x

Wright I. M. (2018) Fractures of the proximal sesamoid bones. In: Nixon A. J. (ed) Equine Fracture Repair. John Wiley \& sons, 430-448 